\title{
Neuroblastoma Children's Cancer Society
}

National Cancer Institute

\section{Source}

National Cancer Institute. Neuroblastoma Children's Cancer Society. NCI Thesaurus.

Code C39475.

The Neuroblastoma Children's Cancer Society is an advocate group dedicated to serving as a support center for children who suffer from neuroblastoma and their families and to fundraising and funding research efforts to develop new modalities of childhood neuroblastoma treatment. 